\title{
Lymphangiogenesis: from the pig embryos to cancer
}

\author{
Linfangiogênese: de embriōes de suinos ao câncer
}

Adhemar Longatto Filho'; Maria Duarte ${ }^{2}$; Fernando C. Schmitt ${ }^{3}$

\section{key words}

Lymphangiogenesis

Metastasis

Endothelium

Lymphatic vessel density

\section{abstract}

The discovery and the comprehension of lymphatic vessels suffered several historical delays and setbacks. The inherent anatomical problems slowed down the precise identification of the lymphatic system during the development of medical science. Gasparo Aselli, an Italian surgeon and anatomist, was the first to describe the lymphatic vessels in 1627 (De Lacteibus sive Lacteis Venis). However, most original descriptions that report the morphology of the lymphatic system in different organisms were done during the 19 th and the 20 th centuries. The recent identification of specific lymphatic vasculature molecular markers allows a more accurate identification and characterization of the lymphatic system evolution in different organs, as well as its role in different pathological conditions, including cancer. This study summarizes the current understanding of lymphangiogenesis in tumour progression, as well as it presents a review of the promising data regarding the prognostic value of lymphatic density and the use of therapeutic lymphangiogenic molecules.

\section{resumo}

A descoberta dos vasos linfáticos e sua compreensão enfrentaram uma série de atrasos e dificuldades históricos. As inerentes dificuldades anatômicas retardaram a identificação precisa da rede vascular linfática durante o desenvolvimento da ciência médica. Gasparo Aselli, um anatomista e cirurgião italiano, foi o primeiro a descrever os vasos linfáticos, em 1627 (De Lacteibus sive Lacteis Venis). Entretanto, a maioria das descrições originais que relatam a morfologia do sistema linfático nos diferentes organismos foi realizada depois, entre os séculos XIX e XX. A recente identificação de marcadores moleculares específicos à vasculatura linfática permite agora identificação e caracterização mais acuradas da evolução da rede linfática nos vários órgãos e em diferentes situações, inclusive no câncer. Esta revisão resume o conhecimento sobre a linfangiogênese na progressão tumoral, bem como apresenta uma síntese dos dados mais promissores em relação ao valor prognóstico da densidade linfática e da utilização das moléculas linfangiogênicas como alvo terapêutico.

1. MSc, PhD, PMIAC; Life and Health Sciences Research Institute, Health Sciences School, Universidade do Minho, Braga, Portugal; Pathology Division, Instituto Adolfo Lutz. 


\section{Introduction}

The lymphatic system is composed of a complex vascular network of thin-walled collecting vessels, which drain lymph from the extracellular spaces within most organs into larger thicker-walled collecting trunks. Physiologic functions of lymphatic vessels include the critical draining tissue fluid back to the blood circulation of plasma proteins, and cells from tissues and organs, particularly during the remodelling process. The lymphatic system also contributes to the body immune surveillance, absorbing lipids from the intestinal tract. Differently from the blood vascular system, the lymphatic vasculature does not form a circulatory system; the lymph flow is unidirectional from tissues back to blood circulation ${ }^{(13)}$. Presently, lymphangiogenesis (the growth of newly formed lymphatic vessels) can also be closely associated to several pathological conditions, such as lymphedema, rheumatoid arthritis, diabetic retinopathy, and arteriosclerosis and tumour progression ${ }^{(2)}$. For most malignant neoplasms, such as colorectal carcinoma, gastric cancer, head and neck squamous cell carcinomas, and melanoma, among others, lymphangiogenesis has been identified as an important clinical finding and is related to poor outcome ${ }^{(17)}$; for others, as breast carcinoma, the real meaning of lymphangiogenesis as a prognostic parameter is still disputable ${ }^{(10)}$. Importantly, lymphatic markers can be used to identify lymphatic vessels also in vascular tumours ${ }^{(16)}$.

Malignant cell differentiation programs encode the metastatic phenotype, by means of additional genetic or epigenetic alterations that determine the tumour cell ability to invade. Morphological differences between blood and lymphatic vessels will certainly influence the preferential escape route, and the peritumoral lymphatics might be considered an easy conduit to be invaded by tumour cells that are ineffective to traverse blood vessel endothelial boundaries ${ }^{(17)}$

\section{Mechanisms for attracting malignant cells}

There are active mechanisms for attracting malignant cells towards one type of vasculature versus another related to inflammatory cells and haematopoietic precursor cells. Active recruitment of tumour cells towards endothelial lymphatics and stromal cells may occur via epidermal growth factor (EGF)-EGF receptor (R)-mediated chemotaxis, since macrophages have been found in proximity to lymphatic vessels ${ }^{(26)}$. Remarkably, macrophages were reported to transdifferentiate into lymphatics in response to inflammation in the eye cornea model ${ }^{(11)}$. Complementary, lymph node secretion of chemokines, such as straight carapace length/curved carapace length (SCL/CCL) 21 and CCL1, may attract tumour cells that express receptors CCR7 and CCR8, respectively ${ }^{(26)}$. Nevertheless, other factors most probably induce primary tumours metastization via blood or lymphatic vessel.

The lymphatic system is an outstanding conduit for neoplastic propagation, since the initial lymphatic vessels are greatly outsized when compared with blood capillaries and, as advantage for invasion efficacy, do not possess a continuous basal membrane. Additionally, the velocity of liquid stream inside the lymphatic channels is much lower than that observed in blood system that makes possible cell preservation and facilitates cell adhesion to escape away from lymphatic system; also the composition of lymph is extremely comparable to the interstitial fluid, contributing in this way towards an increase in cell viability ${ }^{(15)}$.

For many years, the lack of immunohistochemical markers to accurately discriminate lymphatic endothelial cells (LEC) limited the accurate lymphangiogenesis evaluation in cancer setting and metastasis ${ }^{(17)}$. Metastization is a multifaceted process involving changes in the expression of different genes. The lymphatic invasion comprehends a complex interaction of several factors as intratumoral and peritumoral interstitial pressures, a number of molecules related to cell adhesion molecules, specific micro-anatomic structures in lymphatic capillaries and tumour growth within lymphatic vessels ${ }^{(13)}$.

The study of lymphatic system at the molecular level, analysing the expression profile of different available lymphatic markers in the primary tumour, and correlating this expression with markers of tumour aggressiveness can be of utmost interest for cancer prognostication ${ }^{(20)}$.

\section{Brief homage to Florence Sabin}

The commitment of lymphatic sprouting during embryogenesis was first describe by Florence Sabin, more than a century ago, using pig embryos. She hypothesized that primitive lymph sacs originated early in development, from a selected fraction of endothelial cells (ECs) that bud from the veins. The peripheral lymphatic system extends from these primary lymph sacs into the surrounding tissues and organs by endothelial sprouting, originating local capillaries ${ }^{(13)}$. Huntington and McClure, in 1910, proposed an alternative model, where lymph sacs are believed to arise 
independently in mesenchyme, and afterward ascertain the venous connections ${ }^{(13)}$. Almost one century after these remarkable investigations, several articles described a plethora of cells, genes and proteins that control the different steps of embryonic and adult lymphangiogenesis, corroborating Sabin's hypothesis ${ }^{(2,13)}$. Briefly, the embryonic angioblasts are able to develop a primitive vascular net (vasculogenesis) that originates the primitive blood vessel conduits. From the embryonic veins, lymphatic commitment occurs in part of ECs by means of an unknown stimulus. At this point, Prox-1+ ECs are capable of initiating the lymphatic differentiation and sprouting $^{(13)}$ (Figure 1).

\section{The molecular players of lymphangiogenesis}

A number of molecules have been recognized as essential in the signalling cascade for lymphangiogenic sprouting. Lymphangiogenesis comprises a multifarious system of greater complexity than supposed in the past. Fibroblast growth factor (FGF)-2, platelet-derived growth factor- $B$ and hepatocyte growth factor are some of the important molecules currently recognized to stimulate lymphatic vessel growth ${ }^{(1)}$. Conversely, the essential signals for lymphatic differentiation are provided by the homeobox transcription factor Prox 1 and vascular endothelial growth factor (VEGF)-C ${ }^{(2)}$. But there are also other molecules that are critical for lymphatic conduit arrangements. Lymphatic vessel hyaluronan receptor-1 (LYVE-1) is the first embryonic marker of lymphatic endothelial commitment. In adults it is downregulated in the large collecting lymphatic vessels but remains highly expressed in lymphatic capillaries(7). Podoplanin is a transmembrane mucoprotein recognized by the recently commercially available D2-40 monoclonal antibody. D2-40 reacts with a sialoglycoprotein found in lymphatic endothelium and it is supposed to be highly efficient in discriminating lymphatic and blood vessels, with a great potential for use in clinical practice ${ }^{(14)}$ (Figure 2). Although podoplanin function remains unclear, it has been already demonstrated that its expression is regulated by Prox-1 ${ }^{(25)}$. Interestingly, podoplanin is also present in mesothelial cells, osteocytes, glandular myoepithelial cells, ependymal cells, stromal reticular cells and follicular dendritic cells of lymphoid organs. Podoplanin is also strongly expressed by granulosa cells in normal ovarian follicles, and by ovarian dysgerminomas and granulosa cell tumours. Despite the fact that podoplanin is primarily absent in normal epidermis, its conspicuous expression in squamous cell carcinomas was reported, what strongly suggests a potential role of podoplanin in tumour progression ${ }^{(25)}$.

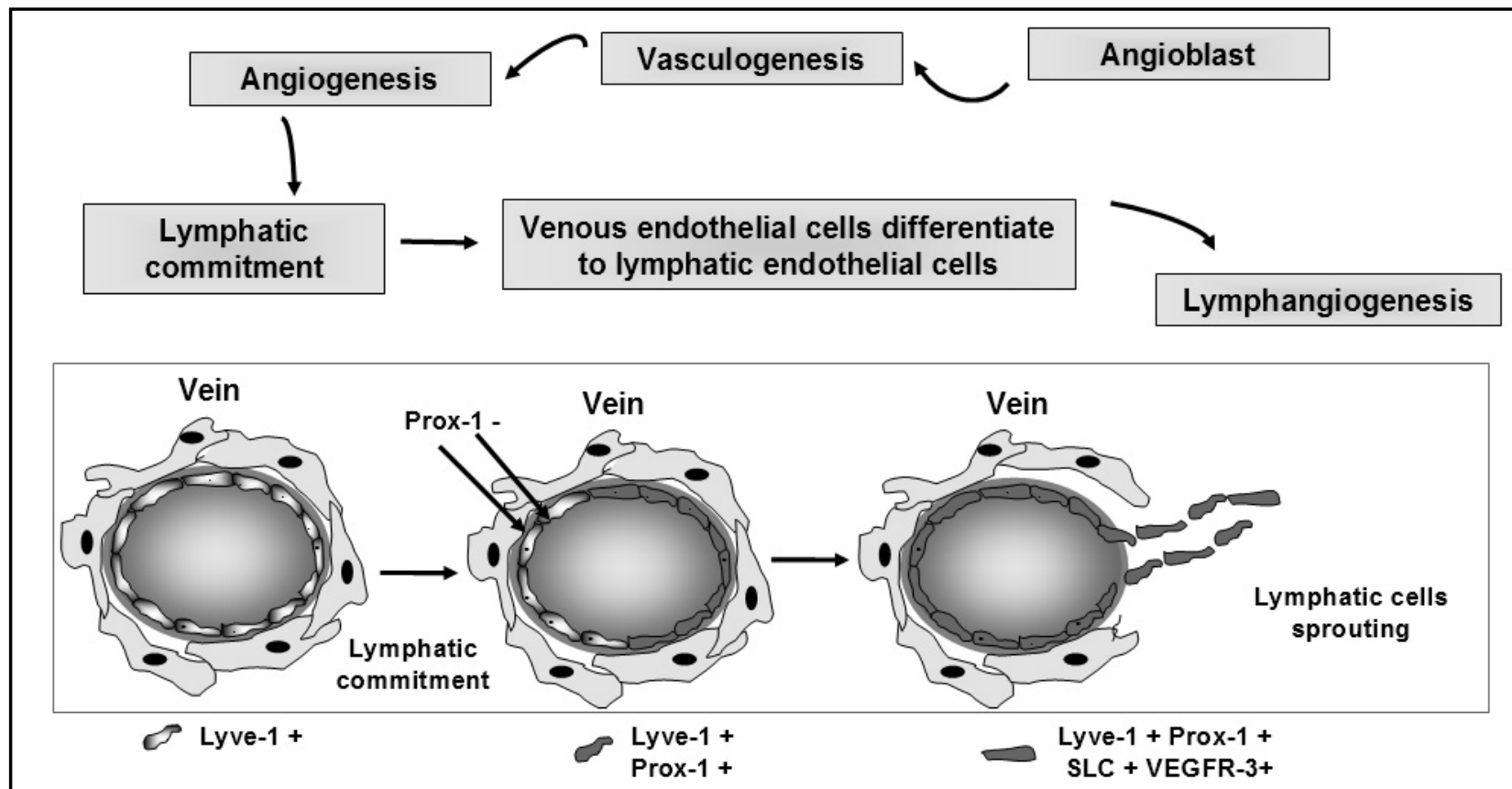

Adapted with permission from Oliver \& Detmar. Genes Dev, v. 16, p. 773-83, 2002.

Figure 1 - Simplified representation of embryonic human lymphatic vessel differentiation. After the blood vessel net formation, endothelial lymphatic commitment occurs and the lymphatic conduits are developed 


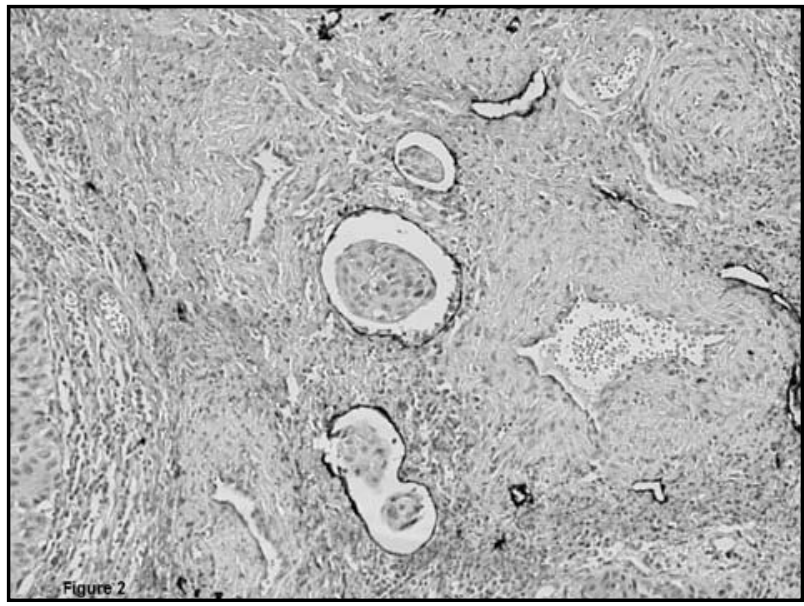

Figure 2 - D2-40 positive immunoreaction in uterine cervix squamous cell carcinoma highlighting lymphatic vessels and lymphatic invasion (400x)

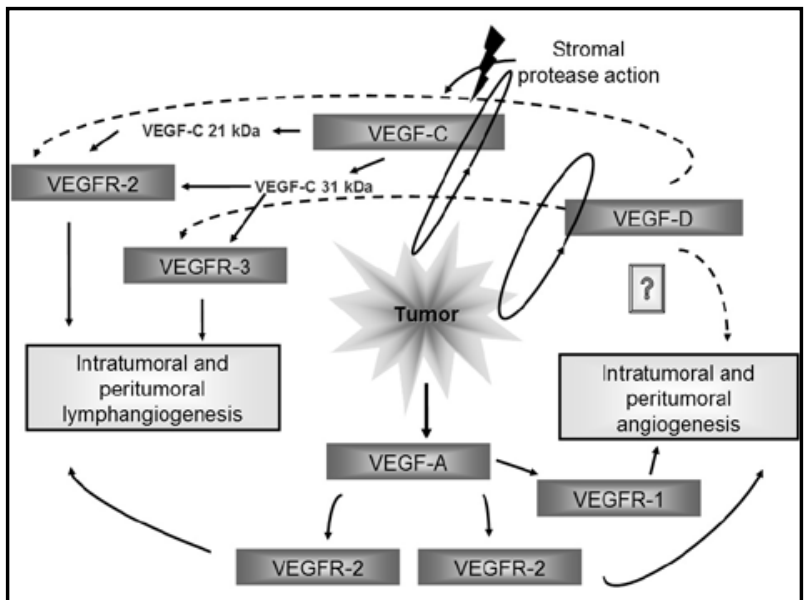

Figure 3 - Basic mechanisms of lymphangiogenesis in cancer setting based on VECF family activities. Note that the molecular cross-talk with angiogenic differentiation is also observed

receptor (FGFR) 3, which is upregulated by Prox-1 in newly formed lymphatic vessels during embryogenesis throughout development ${ }^{(21)}$. This up-regulation is mediated at the transcriptional level by a direct binding of Prox-1 to the specific sequence elements in the FGFR3 gene promoter. Furthermore, FGF1 and FGF2 bind to the low- and high-affinity receptors in LECS promoting migration, proliferation, and cell survival of these cells. FGF2-mediated migration is not dependent on the VEGF-C/VEGFR-3 signalling pathway, strongly suggesting that FGF ligands bind to their receptors in LEC, directly playing a role in lymphatic vessel formation. The FGF signalling plays an important role in a broad range of biological processes of vascular ECs, modifying the adhesiveness or the mechanical integrity of the extracellular matrix, thereby regulating endothelial vascular growth, proliferation, migration, differentiation, survival, tubulogenesis, and differentiation of vascular system. Recently, we identified a new cross-talk between FGF1 and protease-activated receptor (PAR)-1, one of the four thrombin receptors, highly expressed in ECs. There are emerging evidences that PAR 1 modulates cell proliferation and motility in physiological cell invasion process, suggesting its role in the setting of cancer growth and metastasis. Indeed, the overexpression of PAR1 is directly correlated with the invasion and the metastatic potential of a malignant tumour, such as breast carcinoma. In this newly described cross-talk, we found that activation of PAR1 signalling mechanisms leads to an increase of FGF1 expression and its release. Since FGF1 is a well-known mitogen for different cell types, it is strongly possible that PAR1 overexpression holds the capacity to induce abnormal growth, leading to invasion and metastization throughout FGF1 induction, needed as pro-angiogenic factor at the early steps of vascular modelling ${ }^{(6)}$. 


\section{Translational usefulness of Iymphatic expression}

The overwhelm celebrity of lymphatic vessels in the last years are consequence of a great number of remarkable standpoints related to the widespread roles of lymphaticassociated molecules in embryonic development, tissue repair and inflammation, and congenital or acquired dysfunctions of the lymphatic system, resulting in the formation of lymphedema, and vascular malformations. Interestingly, several evidences suggest an active role of malignant tumours in the induction of intratumoral and peritumoral lymphangiogenesis ${ }^{(12)}$. For this reason, the evaluation of lymphatic vessel density can bring useful information to the tumour management ${ }^{(17)}$.

It is well documented that intratumoral lymphatic vessels in tumour xenografts as well as in human tumours overexpress VEGF-C or VEGF-D(9). An outstanding so far crucial issue is whether intratumoral VEGFR-3/LYVE1 positive vessels are functional lymphatics. In fact, lymphangiography examination by intravital microscopy, after injection of dyes in experimental animal models of implanted and spontaneously arising tumours, elegantly reveals that lymphatic vessels in the periphery of tumours are enlarged and perfused, but compressed and nonfunctional within tumour ${ }^{(8)}$. Neoplastic cells growing in a restricted area produce mechanical pressure, which compresses the weakly newly formed lymphatic channels inside the tumour, while at the periphery, excess VEGF-C induces LEC growth, which facilitates lymphatic invasion. Importantly, absence of functional lymphatics within tumours may contribute to interstitial hypertension and interfere with the delivery of therapeutic agents. However, several data strongly sustain the assumption that enhanced numbers of LECs neighbouring the malignant neoplasia facilitate metastasis escape to regional lymph nodes by providing a greater number of entry sites for the invading tumour cells into the lymphatic system ${ }^{(22)}$.

\section{Discussion}

A well-accepted protocol to counting the positive lymphatic vessels stained by a specific marker is not completely established. The number of different proposals seriously compromised the reproducibility, and some results are conflicting. Additionally, there is also high intra- and interobserver variability in lymphangiogenesis quantification. Recently, a preliminary effort to standardize immunohistochemical lymphangiogenesis assessment was reported ${ }^{(23)}$. This purpose is now available and its impact as a clinically useful parameter will be known prospectively. Certainly, this argument will still remain a contentious matter because the method elected to assess lymphatic vessels density (LVD) is far from being consensual. Regularly, and by analogy to angiogenesis, lymphatic immunostained vessels in tumour sections has been evaluated according to Weidner et al. ${ }^{(24)}$, where LVD is determined in vascular "hot spots" or areas giving the impression, at low magnification, of containing numerous stained microvessels at $20 x$ magnification. The reproducibility of this method is questionable, since it depends on the investigator's training and experience ${ }^{(23)}$. Therefore, Chalkley counting method was considered more useful to assess LVD in tumour setting ${ }^{(23)}$. This method involves the use of an eyepiece reticule containing 25 randomly positioned dots, which is rotated so that the maximum number of points is on or within the vessels of the vascular "hot spot". Consequently, as a replacement for counting individual microvessels, the overlaying dots are counted, which means that the obtained value indicates a relative area occupied by lymphatic vasculature, avoiding the subjective decision whether adjacent stained structures are separate microvessels or not ${ }^{(23)}$. Indeed, stained overlapped-vessels are sometimes impossible to be discriminate, for this reason, these conflicting structures are assumed as "one" lymphatic unit ${ }^{(16)}$.

As mentioned before, there is still a major disagreement about the role of intratumoral versus peritumoral lymphatic vessels in solid tumours. Important controversial data have been reported showing that peritumoral LVD is more importantly associated with the presence of metastases than intratumoral LVD ${ }^{(18)}$. Conversely, there are data demonstrating that intratumoral vessels are critical for lymphatic metastasis ${ }^{(3)}$. Interestingly, it was reported that, in melanomas, the size of peritumoral lymphatic vessels is the most significant independent factor that correlates with metastasis ${ }^{(5)}$. Possibly these apparently contradictory results are not feasible to be solved. Recently, Zhang et al. ${ }^{(28)}$ described distinctive signatures for specific peptides in lymphatic vessels in different malignant and premalignant lesions, hypothesizing that tumour development is associated with organ- and stage-specific changes in lymphatics and, more particularly, that lymphatic vessels exhibit also molecular specificities as tumorigenesis progresses. This is an enormous motivating challenge because if this assumption is true, the role of lymphatic spread in tumour setting might be exhaustively investigated in varied series of different types of cancer in order to assess the specific characteristics of LVD in each one of them.

\section{Conclusions}

LVD is not necessarily indicative of the ongoing lymphangiogenesis. To improve this lack of information, the use of a cell cycle marker is encouraged, preferentially in double-stained reaction. Lymphatic cells proliferation can be evaluated by a double immunostaining with antibodies directed to a LEC marker such as D2-40 or LYVE-1 associated to a marker of proliferating cells, Ki-67 or PCNA. Considering the accumulated experience with commercial antibodies, D240 and Ki-67 are two most qualified for this purpose ${ }^{(23)}$. 


\section{Perspectives}

The celebrity presently attributed to the study of lymphangiogenesis is consequence of the astonishing knowledge emerged from the recent studies where a number of new molecular signalling was identified and correlated to critical physiologic and pathological conditions. However, its importance in the metastatic spread of tumours still needs more information to be adequately elucidated. Additionally, given the importance of lymphangiogenesis and its regulators in both lymphatic and blood vessels spreading, a number of strategies aimed at inhibition of these pathways are under investigation ${ }^{(13)}$.

\section{References}

1. ACHEN, M.G.; STACKER, S.A. Tumor Iymphangiogenesis and metastatic spread: new players begin to emerge. Int J Cancer, v. 119, p. 1755-60, 2006.

2. ALITALO, K.; TAMMELA, T.; PETROVA, T. V. Lymphangiogenesis in development and human disease. Nature, v. 438, p. 946-53, 2005

3. AUDET, N. et al. Lymphatic vessel density, nodal metastases, and prognosis in patients with head and neck cancer. Arch Otolaryngol Head Neck Surg, v. 131, p. 1065-70, 2005.

4. BJORNDAHL, M. A. etal. Vascular endothelial growth factor-A promotes peritumoral lymphangiogenesis and lymphatic metastasis. Cancer Res, v. 65, p. 9261-8, 2005.

5. DADRAS, S. S. et al. Tumor lymphangiogenesis: a novel prognostic indicator for cutaneous melanoma metastasis and survival. Am J Pathol, v. 162, p. 1951-60, 2003.

6. DUARTE, M. et al. Thrombin induces rapid PAR1-mediated non-classical FGF1 release. Biochem Biophys Res Commun, v. 350, p. 604-9, 2006.

7. JACKSON, D. G. New molecular markers for the study of tumor lymphangiogenesis. Anticancer Res, v. 21, p. 4279-83, 2001.

8. JAIN, R. K.; FENTON, B. T. Intratumoral lymphatic vessels: a case of mistaken identity or malfunction? J Natl Cancer Inst, v. 94, p. 417-21, 2002.

9. KARPANEN, T. et al. Functional interaction of VEGF-C and VEGF-D with neuropilin receptors. FASEB J, v. 20, p. 1462-72, 2006

10. LONGATTO FILHO, A. et al. VEGFR-3 expression in breast cancer tissue is not restricted to lymphatic vessels. Pathol Res Pract, v. 201, p. 939, 2005.

11. MARUYAMA, K. et al. Inflammation-induced lymphangiogenesis in the cornea arises from CD11bpositive macrophages. J Clin Invest, v. 115, p. 236372, 2005.

12. OLIVER, G.; ALITALO, K. The lymphatic vasculature: recent progress and paradigms. Ann Rev Cell Dev Biol, v. 21, p. 457-83, 2005.

13. OLIVER, G.; DETMAR, M. The rediscovery of the lymphatic system: old and new insights into the development and biological function of the lymphatic vasculature. Genes Dev, v. 16, p. 773-83, 2002.

14. ORDONEZ, N. G. Podoplanin: a novel diagnostic immunohistochemical marker. Adv Anat Pathol, v. 13, p. 83-8, 2006.

15. PEPPER, M. S. Lymphangiogenesis and tumor metastasis. Myth or reality? Clin Cancer Res, v. 7, p. 462-8, 2001.

16. REIS, R. M. et al. Differential Prox-1 and CD 31 expression in mucousae, cutaneous and soft tissue vascular lesions and tumors. Pathol Res Pract, v. 201, n. 12, p. 771-6, 2005.

17. REIS-FILHO, J. S.; SCHMITT, F. C. Lymphangiogenesis in tumors: what do we know? Micros Res Tech, v. 60, p. 171-80, 2003.

18. ROMA, A. A. Peritumoral lymphatic invasion is associated with regional lymph node metastasis in prostate adenocarcinoma. Mod Pathol, v. 19, p. 392-8, 2006

19. ROY, H.; BHARDWAJ, S.; YLA-HERTTUALA, S. Biology of vascular endothelial growth factors. FEBS Lett, v. 580, n. 12 , p. 2879-87, 2006

20. SAHARINEN, P.; PETROVA, T. V. Molecular regulation of lymphangiogenesis. Ann N Y Acad Sci, v. 1014, p. 76-87, 2004

21. SHIN, J. W. et al. Prox1 promotes lineage-specific expression of fibroblast growth factor (FGF) receptor-3 in lymphatic endothelium: a role for FGF signaling in lymphangiogenesis. Mol Biol Cell, v. 17, p. 576-84, 2006.

22. THIELE, W.; SLEEMAN, J. P. Tumor-induced lymphangiogenesis: a target for cancer therapy? J Biotechnol, v. 124, p. 224-41, 2006.

23. Van der AUWERA, I. etal. First international consensus on the methodology of lymphangiogenesis quantification in solid human tumours. Br J Cancer, v. 95, p. 1611-25, 2006.

24. WEIDNER, N. et al. Tumor angiogenesis and metastasis: correlation in invasive breast carcinoma. N Engl J Med, v. 324, p. 1-8, 1991.

25. WICKI, A.; CHRISTOFORI, G. The potential role of podoplanin in tumour invasion. Br J Cancer, v. 96, n. 1, p. 1-5, 2007.

26. WONG, S. Y.; HYNES, R. O. Lymphatic or hematogenous dissemination: how does a metastatic tumor cell decide? Cell Cycle, v. 5, p. 812-7, 2006.

27. YAMAZAKI, Y.; MORITA, T. Molecular and functional diversity of vascular endothelial growth factors. Mol Divers, v. 10, p. 515-27, 2006.

28. ZHANG, L. et al. Lymphatic zip codes in premalignant lesions and tumors. Cancer Res, v. 66, p. 5696-706, 2006. 